\title{
Comparisons of fauna among natural and transplanted eelgrass Zostera marina meadows: criteria for mitigation
}

\author{
Mark S. Fonseca, W. Judson Kenworthy, David R. Colby, Keith A. Rittmaster, \\ Gordon W. Thayer
}

National Marine Fisheries Service, Southeast Fisheries Center, Beaufort Laboratory, Beaufort, North Carolina 28516, USA

\begin{abstract}
Numerical abundance, species composition and size of fish and shrimp were compared among (1) unvegetated, (2) transplanted, (3) recently seed-colonized, and (4) mature, natural eelgrass habitats to determine the equivalence of transplanted eelgrass beds to their natural counterparts. In general, fish and shrimp were most abundant in mature natural eelgrass habitats and least abundant in unvegetated habitats. We developed a vector-graphical analysis that shows epibenthic faunal abundance to be closely coupled with eelgrass bed development. In an area where transplants performed poorly, the faunal component had a different composition and significantly lower numerical abundance in comparison to natural beds. Faunal abundance and composition in a 1.9-yr-old transplanted bed and a 6-mo-old seed-developed bed were indistinguishable from mature natural eelgrass beds. Our data indicate that recruitment of fish and shrimp to eelgrass habitats established through transplantation can occur in time, though not as rapidly as with naturally-seeded beds. Areal shoot density may serve as an inexpensive diagnostic parameter of functional equivalence for most resident macroepifauna. Abundance data need to be interpreted through functional mechanisms such as predation which act to produce the observed abundances in order to separate habitat function from dysfunction. Restored seagrass habitats have the potential to make substantial contributions to fish and shrimp production provided the habitats persist.
\end{abstract}

\section{INTRODUCTION}

Seagrasses provide significant feeding, nursery and refuge habitats for ecologically and economically valuable species in the coastal zone (see reviews in Zieman 1982 and Thayer et al. 1984). Restoration and creation of seagrass habitat by transplantation has been widely adopted in the USA as a means of ecological restitution or mitigation for habitat destruction in the coastal zone. There is however, little support for the assumption that artificially-propagated seagrass habitats function ecologically in the same way as their natural counterparts (Race \& Christie 1982, Thayer et al. 1984, Mager \& Thayer 1986, Fonseca et al. 1988). In this paper we compare the fish and shrimp fauna of eelgrass Zostera marina habitats established by transplantation with that in (1) unvegetated habitats, (2) eelgrass habitats arising from recent seedling colonization, and (3) mature, natural eelgrass beds that are known to have been in existence for more than $5 \mathrm{yr}$.
One objective of the study was to relate changes in eelgrass coverage and shoot density to changes in the abundance and species composition of the corresponding fish and shrimp populations, so that rates of eelgrass community development could be inferred. This was attempted both through direct comparisons of faunal abundance in meadows of different ages, and through repeated sampling of the same habitats over time. Because evaluation of coverage and shoot density are relatively inexpensive, we sought to determine if these parameters would provide a reliable diagnostic parameter for evaluation of functional equivalence in terms of resident macroepifauna.

\section{METHODS}

Site description. Dredge Island: The primary study site was located immediately adjacent to an 8 acre (3.2 ha) dredged material island in southern Core 


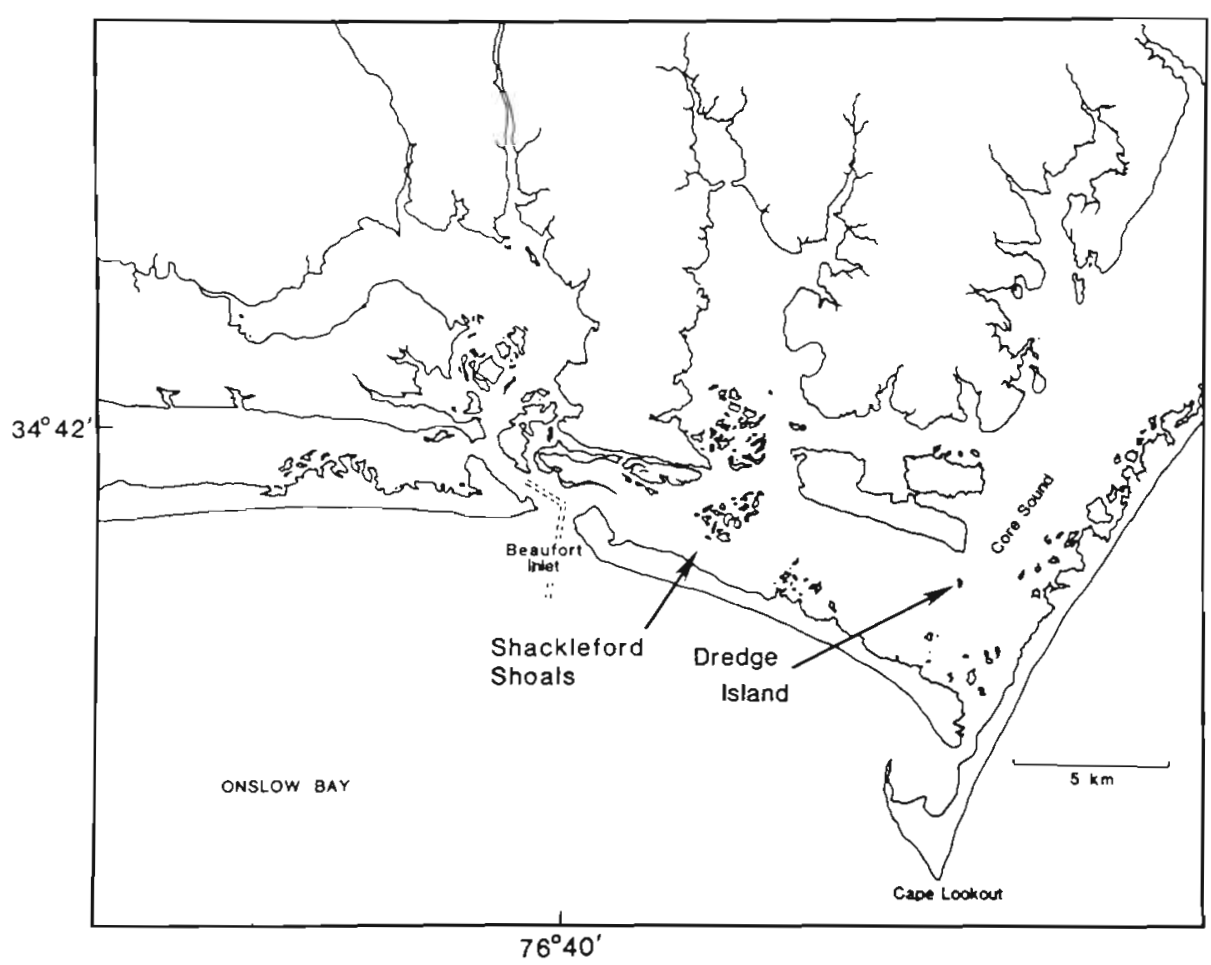

Fig. 1. Location of the 2 study sites, Carteret County, North Carolina, USA
Sound, Carteret County, North Carolina, USA (Fig. 1). The island is located in an open water area with substantial fetches to the northeast and southwest. Unvegetated subtidal areas $(<-1.3 \mathrm{~m}$ MHW) that had previously supported eelgrass cover were adjacent to the south side of the island and available for an attempt at re-establishment of eelgrass habitat by transplantation. Abutting the western edge of the unvegetated areas was an extensive (ca $10 \mathrm{ha}$ ) bed of eelgrass, providing for direct comparison with experimental plantings.

Shackleford Shoals: A second site was used when conditions at the Dredge Island deteriorated. This site was located on a large shoal area $(<-1.5 \mathrm{~m}$ MHW) between Shackleford Banks and Middle Marsh (Fig. 1), near Beaufort Inlet, ca $9 \mathrm{~km}$ west of the Dredge Island.

Sediment composition. The sediment varied little within and between the sites (range of treatment means 0.10 to $0.17 \mathrm{~mm}$ mean particle diameter). Sediments were well to moderately sorted over a leptokurtic distribution skewed toward fine sand after Folk \& Ward (1957).

Experimental design. Dredge Island: One purpose of our study was to compare the fauna of unvegetated habitat with that of naturally established eelgrass habitat and that of eelgrass habitat created by transplantation. A second purpose of the study was to determine if 'edge' effects on faunal abundance could be detected. To accomplish these comparisons, our experimental design utilized both an area of unvege- tated sand bottom created by off-site drift of dredged material, and a portion of the natural eelgrass meadow immediately to the west. There were 2 treatments in the natural eelgrass meadow: those on the edge of the meadow (ne) and those $15 \mathrm{~m}$ inside the meadow (ni) (Fig. 2). Three additional treatments were established by transplanting onto the unvegetated sand bottom. One was simply unmodified bottom, devoid of vegetation (ba); the others were designed to provide high and low perimeter to area ratios (hp and Ip, respectively). Eelgrass was transplanted using techniques described in Fonseca et al. $(1982,1985)$.

All treatments were assigned to $7.5 \times 7.5 \mathrm{~m}$ experimental units. The 5 treatment types were repeated in 5 blocks across the study site (Fig. 2). The placement of the natural meadow treatments was fixed within each block because of the distinct, linear edge of natural eelgrass cover. The remaining 3 treatments in a block were randomly assigned to the 3 remaining experimental units. All treatments were separated by $7.5 \mathrm{~m}$ unplanted buffer areas, except in the natural meadow where eelgrass cover continued across the buffers. The arrangement of treatments within blocks provided 5 replicate samples of each treatment type on the study area, and at the same time controlled for any nearshore-offshore environmental gradient which might bias comparisons among treatments.

Equally spaced around the perimeter of each experimental unit were eight $1.5 \times 1.5 \mathrm{~m}$ potential sampling plots (Fig. 2). At the beginning of the study, these 8 


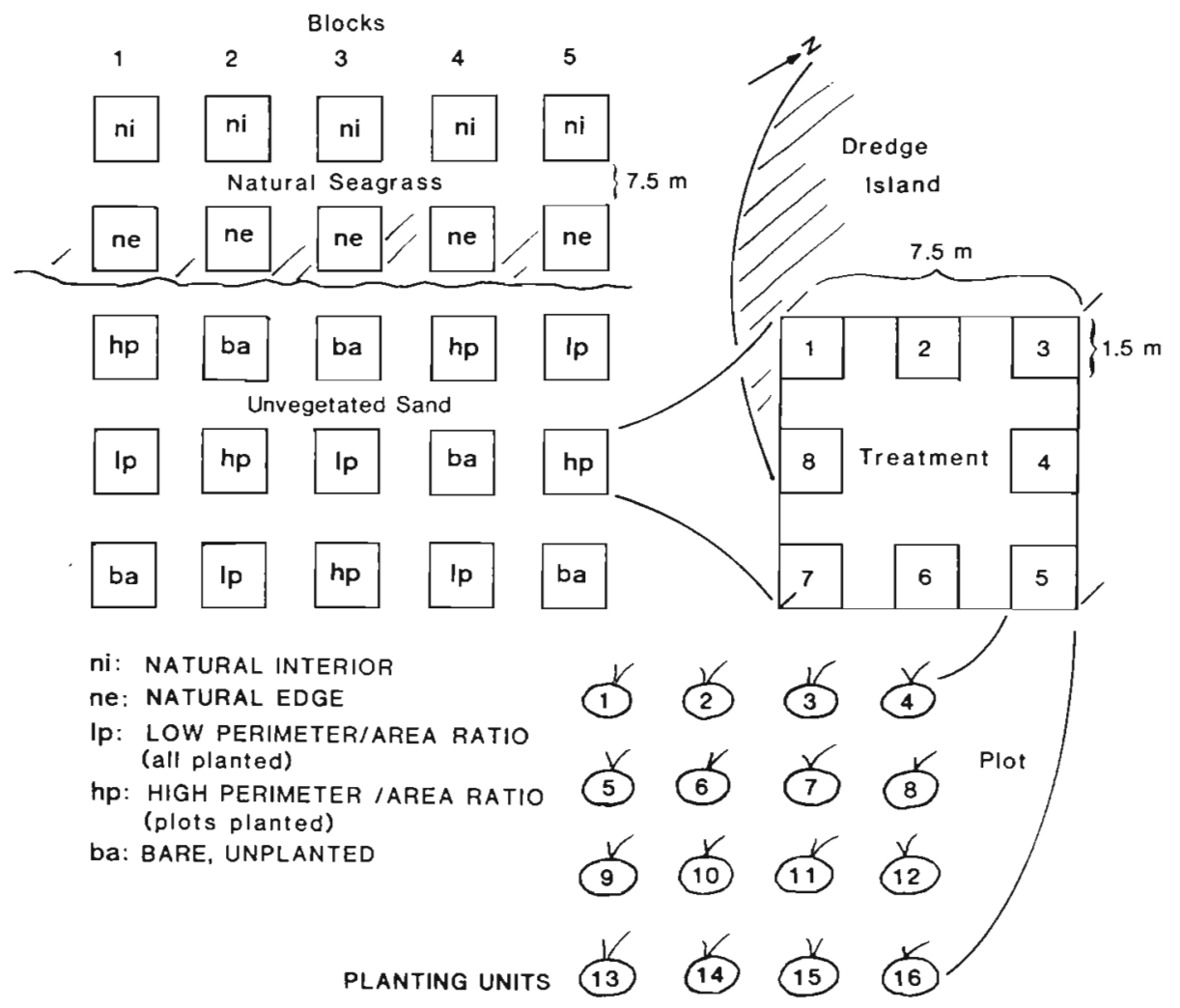

Fig. 2. Experimental design in study area at the Dredge Island site plots were randomly assigned an order of sampling and were sampled no more than once during the study.

Each experimental unit was sampled during January, March, May, July and September 1986. On a given sampling day 5 dropnets were deployed, one on each of the 5 experimental units in a block. This meant that one replicate of each treatment was sampled per day. The order in which the 5 blocks were sampled was determined by random draw, as was the order in which the 5 nets within a block were dropped. The traps within a given block were dropped within one of 5 time intervals, $00: 00$ to $04: 45 \mathrm{~h}, 04: 46$ to $09: 30 \mathrm{~h}, 09: 31$ to $14: 15 \mathrm{~h}$, $14: 16$ to $19: 00 \mathrm{~h}$, and $19: 00$ to $24: 00 \mathrm{~h}$, so that the set of samples from the 5 blocks encompassed the $24 \mathrm{~h}$ day and all tide stages in a balanced fashion. This allowed us to discount day-night and tidal stage effects in our analysis.

The October 1985 transplants did not survive beyond October 1986 (see 'Results'), but the area experienced eelgrass seedling recruitment beginning in December 1986. The seedlings formed a meadow that has persisted to the present time (April 1990), covering the area which had been devoid of vegetation at the initiation of the study. This new, naturally seeded (nns) eelgrass habitat and the adjacent edge of the mature, natural eelgrass bed (nne) were sampled in June 1987 for eelgrass and faunal abundance as previously described except that 3 randomly located dropnets were deployed in each nns and nne area.

Shackleford Shoals: The eelgrass transplants on the Shackleford site had been planted as part of a fertilization study (Fonseca et al. 1987) on October 24, 1984, and on the sampling date (mid-day, September 28, 1986 ), were $704 \mathrm{~d}$ (1.9 yr) old. The configuration of this site was different, being composed of 7 patches, of ca $2 \mathrm{~m}$ diameter, remaining from the fertilization experiments, with adjacent, natural eelgrass patches of similar size. All fertilizer had been solubilized at least $1 \mathrm{yr}$ prior to our sampling. We used this site to represent a later developmental stage for comparison with the Dredge Island site. Two of the transplanted patches (sst) were randomly selected, while 2 natural patches (ssn), and 2 unplanted, bare areas were arbitrarily selected from within a $50 \mathrm{~m}$ radius of the fertilizer plots.

Seagrass sampling. Dredge Island: In transplanted areas shoot counts were performed at least $12 \mathrm{~h}$ before faunal sampling. Three randomly selected planting units of those remaining within the plot were surveyed for number of shoots and area covered per planting unit. Shoot numbers were obtained by direct counts while coverage was measured by placing a $0.5 \times 0.5 \mathrm{~m}$ quadrat subdivided by strings on $5 \mathrm{~cm}$ centers over the planting unit. The number of $5 \times 5 \mathrm{~cm}$ squares or half- 
squares with eelgrass shoots in them were tallied to estimate coverage.

In natural eelgrass areas, coverage and density were sampled with a $1.5 \times 1.5 \mathrm{~m}$ quadrat that covered the entire experimental unit. The quadrat was subdivided by strings on $0.25 \mathrm{~m}$ centers, creating 36 squares $0.25 \mathrm{~m}$ on a side. The number of squares and halfsquares with cover (area where the rhizomes overlapped) was recorded. Three of these squares were randomly selected and the number of shoots were recorded for density estimation. Areas that were apparently bare were nonetheless sampled to verify the absence of cover and/or the colonization by shoalgrass Halodule wrightii or eelgrass.

Eelgrass sampling in the newly seeded bed (June 1987) was conducted in a similar manner to the natural beds. Instead of 5 blocks, the edge of the original, natural bed was marked off as a sampling area $66.5 \times$ $22.5 \mathrm{~m}$ (new, natural edge; nne), as was the adjacent. seeded bed (new, natural seeded, nns). Three random locations within each area were then selected for the dropnets.

Shackleford Shoals: Seagrass sampling was performed in these beds using the same procedure described for the ne, ni, nne, and nns treatments. On this site, the beds were selected so as to be large enough to accommodate the dropnets.

Faunal sampling. Dropnets were used to sample fauna. Each dropnet consisted of a $1.5 \times 1.5 \mathrm{~m}$ sheet metal (18 gauge) square, $23 \mathrm{~cm}$ high. A net curtain $1.5 \mathrm{~m}$ in height and of $0.16 \mathrm{~cm}$ mesh was attached to the top edge of the square, with U-shaped clamps attached to the outside of the square. After the dropnet was manually positioned over a given plot, hollow metal poles were pushed into the sand through each of the 4 clamps to a depth of ca $50 \mathrm{~cm}$. The net was lifted and pins inserted through holes in the poles to support the net until it was dropped. Lines running from each pin to anchors $15 \mathrm{~m}$ away were used to release the pins and drop the net. Nets were dropped no less than $12 \mathrm{~h}$ after deployment.

Fish and shrimp were recovered from the dropnets with seine and dip nets (both $0.16 \mathrm{~cm}$ mesh). Recovery efforts were terminated after no fish or shrimp were taken in 3 successive passes with the seine and 5 successive sweeps with the dip net.

Efficiency of the faunal recovery procedure was verified by deploying 3 dropnets on a sand beach exposed at low tide. As the tide rose and filled the nets, eelgrass was transplanted into the nets at natural densities after which fish and shrimp were released inside the nets. Recovery of both fish and shrimp exceeded $85 \%$.

By assigning blocks to time of day and using dropnets, we eliminated day-night effects and likely sampled only grass bed residents. Previous work (Jacobsen
\& Kushian 1987) has shown that while throw traps of similar size are unbiased in some regards against species, they are biased against size. Sogard et al. (1987) also used throw traps and found no day-night differences of resident fishes and invertebrates. These studies taken together with the size range of fauna we eventually captured suggest that we sampled eelgrass bed residents, which of itself insulates the results from potential day-night and tidal stage effects.

Data analysis. Numerical abundance data for fish and shrimp at the Dredge Island (1986) were highly skewed. Transformation of data by adding 1 and taking the logarithm failed to satisfactorily deal with the problem of heteroscedasticity in a number of cases. Therefore, analyses of variance for testing hypotheses concerning differences in fish and shrimp abundance among treatments were based upon the ranks of the observations rather than the original abundance values. The Student Newman-Keuls test was used for comparisons of treatment means when an F-test indicated significant treatment effects. For a given dependent variable, a separate ANOVA was computed for each sampling period. The statistical model used was that for a randomized, complete block design, even though, of course, the 2 natural seagrass treatments could not be randomly assigned to experimental plots. Ranked ANOVA could not be performed on data from the Shackleford site or the 1987 Dredge Island data because of the small number of replicates.

Faunal composition was compared by percentage similarity matrices (Whittaker \& Fairbanks 1958) as used by Holmquist et al. (1989). These matrices were developed on the species that constituted $99 \%$ of the catch. Percent species shared among paired treatment comparisons also was computed.

The collections provided data for comparisons of both fauna and eelgrass at different points in time. We examined rates of development of the several experimental and natural communities studied, by plotting measures of the faunal community versus measures of eelgrass itself. Arrows connecting successive points in time are vectors and we refer to this approach as vector-graphical analysis. The aim of this type of analysis was to display a 'global' measure of the fauna (e.g. total numbers of individuals collected at a given time) against a corresponding measure of the seagrass (e.g. shoot density) and to examine the vectors connecting samples separated in time. Each of the measures was first scaled by subtracting the overall mean and dividing by the overall standard deviation. On such a graph, vectors having an angle close to a $45^{\circ}$ line extending from the origin would imply that faunal abundance was simply proportional to shoot density. More importantly, however, such a graph depicts, for any particular time interval, the distance (dissimilarity) of a developing 
community from its mature counterpart, and overall the rate at which the former is approaching the latter. Having the ability to describe the developmental trajectory of fauna in transplanted eelgrass as a function of shoot number is central to a decision to use shoot numbers alone as a diagnostic parameter for evaluating functional development.

\section{RESULTS}

\section{Seagrass bed dynamics}

\section{Dredge Island}

The number of surviving planting units (PUs) on the experimental transplant plots at the Dredge Island site steadily declined over the course of the study (Fig. 3). The average number of shoots per planting unit increased sharply from February to March, but thereafter declined (Fig. 3). Despite the loss, the remaining PUs in the transplanted areas continued to grow, increasing total coverage in the spring and early summer, but then declined dramatically (Fig. 4). This combined effect of PU loss and shoot attrition decreased shoot numbers per dropnet sample to zero or near zero (Fig. 5). By September, eelgrass shoots were epiphytized and dull in appearance with brown tips, possibly from desiccation at low tide. High temperatures and salinities associated with a record-breaking drought in the southeast USA in 1986 apparently amplified the normal seasonal summer die-back for Zostera in North Carolina waters to the point where most of the transplants died.

The area covered by natural eelgrass in our 1986 dropnet plots demonstrated little seasonal variation
(Fig.4), but the number of shoots per unit area did (Fig.5). From March to September, shoot density decreased from 2500 to 500 per dropnet. The experimental bare area plots were generally devoid of vegetation but some bare area plots sampled on June 30 contained shoalgrass Halodule wrightii that had recently invaded.

In 1987, a strong eelgrass seed set germinated and spread rapidly over the area of the experimental plots. By June this resulted in a coverage and shoot abundance similar to that shown by the adjacent, natural eelgrass bed the preceding year (Figs. 4 and 5).

\section{Shackleford Shoals}

Eelgrass at this site appeared to be less stressed than at the Dredge Island site as evidenced by intact, bright green leaves on the shoots. The Shackleford site was several kilometers closer to the controlling inlet and thus environmental extremes may have been moderated by oceanic influences. Coverage levels in natural meadows at both Shackleford Shoals and Dredge Island, and in transplanted areas at the Shackleford site, were virtually identical in September (Fig.4). However, shoot densities were slightly higher in the Shackleford Shoals site natural beds (ssn) than at the Dredge Island natural beds (ni, ne) in September (Fig. 5).

\section{Faunal abundance, composition and size}

Overall, the fish catch was 1109 individuals of 32 species in 20 families and the shrimp catch was 7563 individuals of 19 species in 6 families (Table 1a, b). There often were too few of a given species for com-
Fig. 3. Grand mean of the number of planting units (PU) per plot, and the number of shoots per planting unit for transplanted eelgrass at the Dredge Island. Error bars $=1$ standard error. Eelgrass treatment codes: hp, high perimeter/area (P/A); lp, low P/A eelgrass transplants

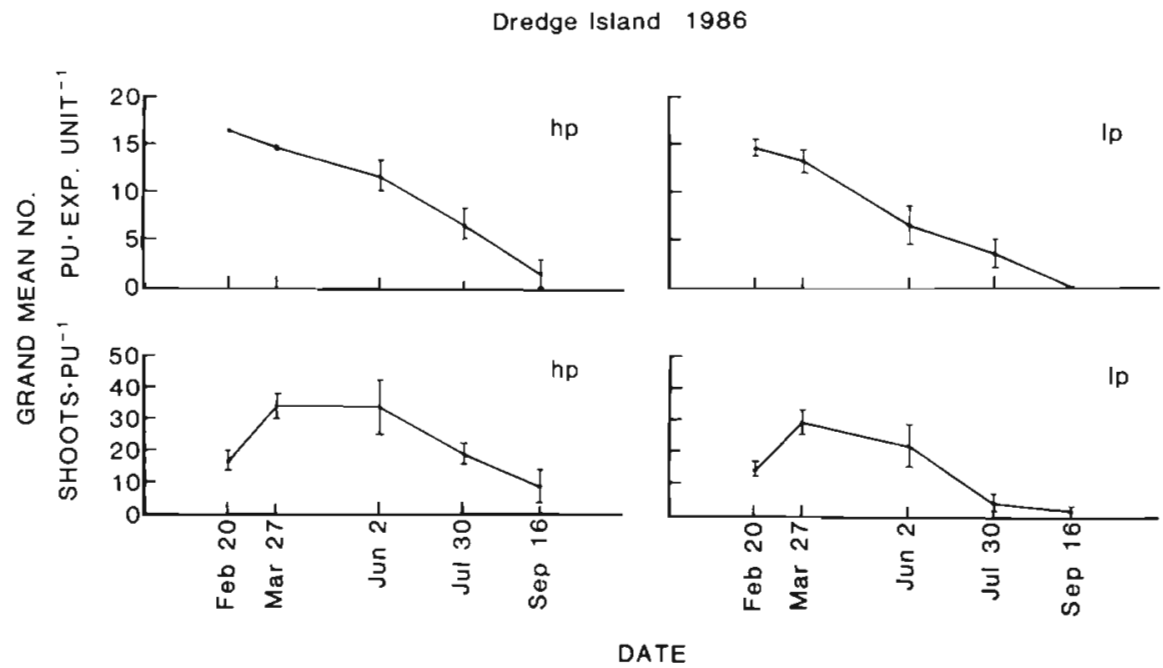




\section{Dredge Island 1986}

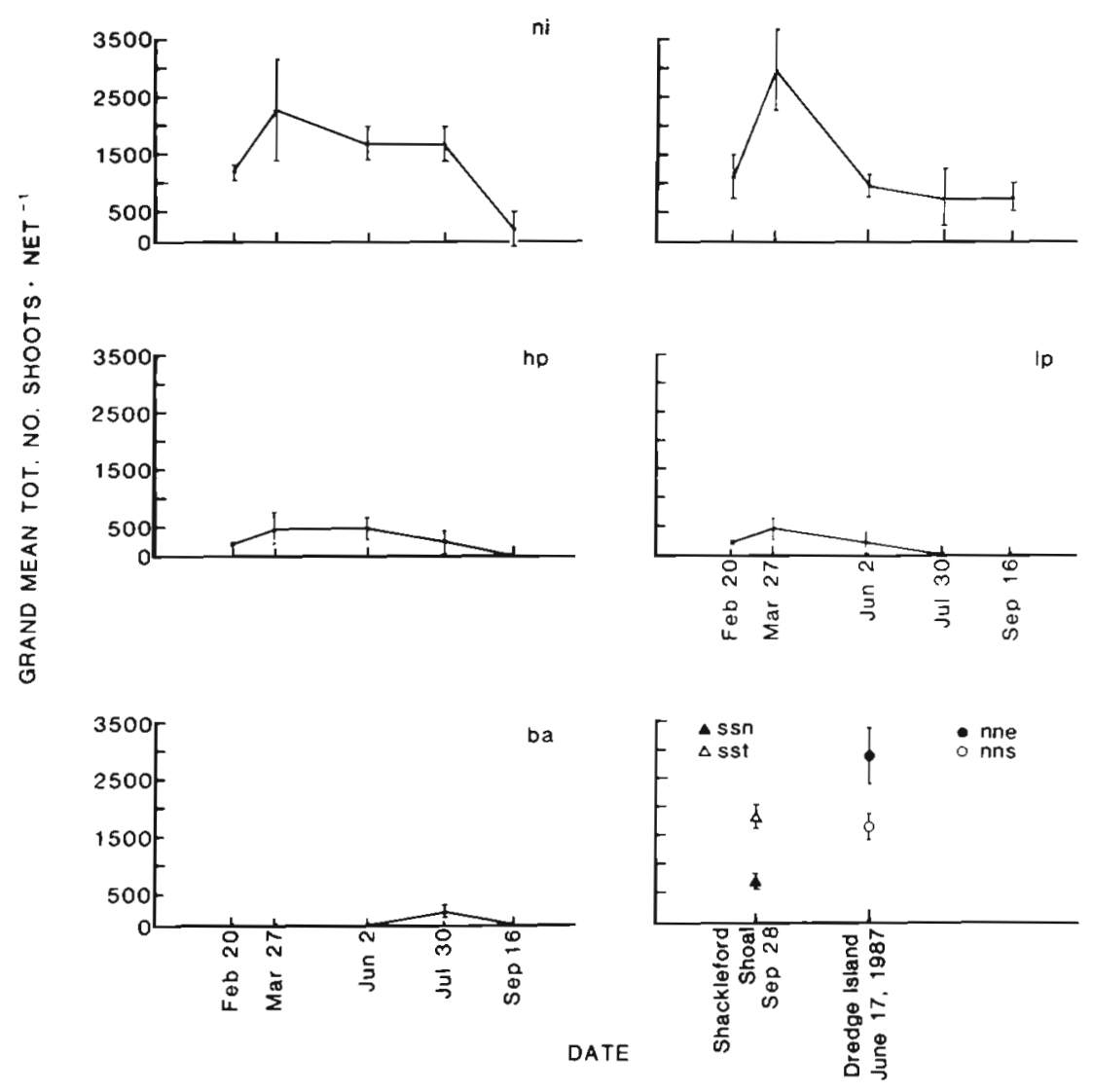

Fig. 4. Grand mean of seagrass cover $\left(\mathrm{m}^{2}\right)$ per $2.25 \mathrm{~m}^{2}$ dropnet. Error bars $=1$ standard error. Dredge Island eelgrass treatment codes: ni, natural interior; ne, natural edge; $e$, high perimeter/area (P/A) transplant; lp, low $\mathrm{P} / \mathrm{A}_{\text {; }}$ ba, bare area; nne, new natural edge; nns new naturally seeded. Shackleford Shoals: ssn, natural; sst, transplanted

\section{Dredge Island 1988}

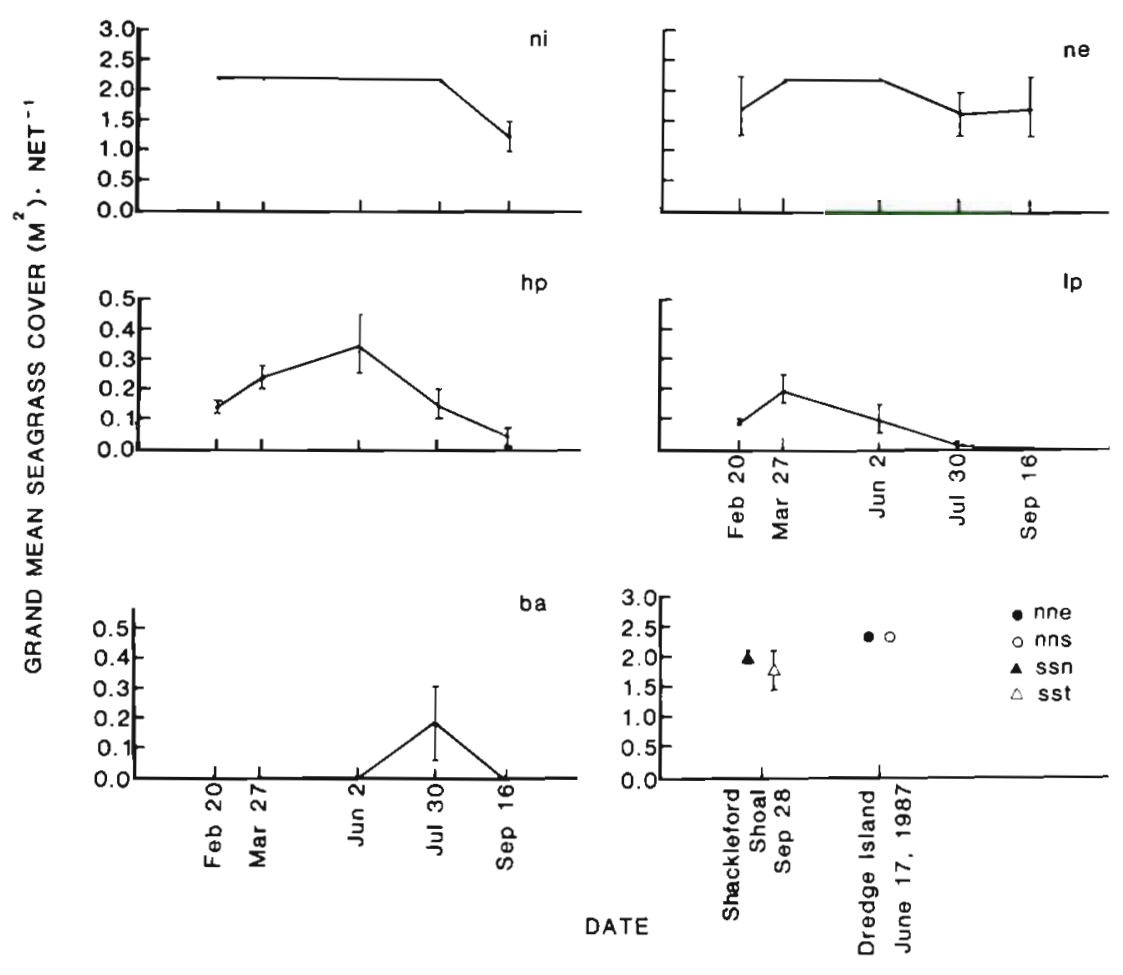

Fig. 5. Grand mean of seagrass shoots per $2.25 \mathrm{~m}^{2}$ dropnet. Error bars = 1 standard error Dredge Island eelgrass treatment codes: ni, natural interior $;$ ne, natural edge; hp, high perimeter/area (P/A) transplant; lp, low $\mathrm{P} / \mathrm{A}$; ba, bare area; nne, new natural edge; nns, new naturally seeded. Shackleford Shoals: ssn, natural; sst, transplanted 
Table 1. Total number of individuals by site, date and species. Values are total numbers in natural, transplanted, bare treatments; in parentheses: fish-average standard length ( $\mathrm{SL}, \mathrm{mm})$; shrimp-average short carapace length (SCL, $\mathrm{mm})$

\begin{tabular}{|c|c|c|c|c|c|c|c|}
\hline \multirow[t]{2}{*}{ Species } & \multicolumn{4}{|c|}{ Dredge Island 1986} & \multicolumn{2}{|r|}{ S. Shoal 1986} & \multirow{2}{*}{$\begin{array}{c}\text { Dredge I. } 198 \\
\text { Jun } 18\end{array}$} \\
\hline & $\operatorname{Jan} 31$ & Mar 13 & May 23 & Jul 18 & Sep 18 & Sep 28 & \\
\hline \multicolumn{8}{|l|}{ a Fish } \\
\hline Leiostomus xanthurus & $2,0,1(8)$ & $319,14,0(18)$ & $3,1,1,(40)$ & & & & \\
\hline Lagodon rhomboides & $2,6,2(11)$ & $202,35,1(14)$ & $65,5,0(35)$ & $1,0,0(65)$ & $17,0,0(64)$ & $0,1,0(96)$ & $11,2(43)$ \\
\hline Orthopristis chrsyoptera & & & $37,0,0(19)$ & $1,0,0(27)$ & & & \\
\hline Syngnathus floridae & $0,1,0(115)$ & $3,0,0(92)$ & $2,0,0(31)$ & $1,1,0(108)$ & $14,4,0(90)$ & $1,0,0(69)$ & $3,2(76)$ \\
\hline Opsanus tau & & & $4,0,0(55)$ & $3,0,0(56)$ & $13,0,0(55)$ & & $1,0(85)$ \\
\hline Eucinostomus gula & & & & $1,1,1(11)$ & $0,10,1(12)$ & $16,3,0(13)$ & \\
\hline Symphurus plagiusa & $0,0,2(22)$ & $2,1,0(27)$ & & $0,10,5(16)$ & $6,8,0(28)$ & $8,2,0(33)$ & $1,1(44)$ \\
\hline Gobionellus boleosoma & & & & & $1,3,0(13)$ & $14,7,0(17)$ & \\
\hline Menidia menidia & & $1,0,0\{89\}$ & $13,0,0(13)$ & & & & \\
\hline Gobiosoma bosci & & & & & $4,2,0(14)$ & $7,0,0(14)$ & \\
\hline Brevoortia tyrannus & & $5,1,5(21)$ & & & & & \\
\hline Anchoa hepsetus & & & & $2,0,0(3)$ & $2,0,0(69)$ & & \\
\hline Anguilla rostrata & $1,0,0(43)$ & $0,0,1(51)$ & & & $3,0,0(145)$ & & \\
\hline Syngnathus fuscus & $1,0,0(90)$ & $1,0,0(86)$ & $1,0,0(36)$ & $1,0,0(89)$ & & & \\
\hline Lutjanus griseus & & & & & $3,0,0(22)$ & & \\
\hline Citharichthys sp. & & $2,1,0(18)$ & & & & & \\
\hline Monacanthus hispidus & & & $1,0,0(15)$ & & $1,0,0(44)$ & & \\
\hline Paralichthys albigutta & & $1,2,0(9)$ & & $1,0,0(56)$ & & & $0,1(195)$ \\
\hline Paralichthys dentatus & & $1,1,0(13)$ & & & & & \\
\hline Urophycis regia & & $2,2,0(28)$ & & & & & \\
\hline Chasmodes bosquianus & & & $1,0,0(55)$ & & & & \\
\hline Hippocampus erectus & & & $1,0,0(10)$ & & $0,1,0(70)$ & & \\
\hline Membras martinica & & & & $1,2,0(18)$ & $0,6,1(37)$ & & \\
\hline Micropogonias undulatus & & $0,0,1(12)$ & & & & & \\
\hline Mycteroperca microlepis & & & $1,0,0(20)$ & & & & \\
\hline Myrophis punctatus & & $1,1,1(57)$ & & & & & \\
\hline Aluterus schoepfi & & & & & $0,0,1(120)$ & & \\
\hline Centropristis striata & & & & & & $0,1,0(83)$ & \\
\hline Hypleurochilus germinatus & & & & & & $0,1,0(21)$ & \\
\hline Unidentified fish & $7,1,0(-)^{a}$ & & & & & $1,0,0(6)$ & \\
\hline Archosargus probatocephalus & & & & & & & $1.0(11)$ \\
\hline Bairdiella chrysoura & & & & & & & $3.5(9)$ \\
\hline \multicolumn{8}{|l|}{ b Shrimp } \\
\hline Hippolyte pleuracanthus & $12,0,0(2)$ & $235,13,2(2)$ & $216,10,0(2)$ & $832,60,12(2)$ & $270,35,0(2)$ & $142,88,0(2)$ & $242,217(2)$ \\
\hline Hippolyte zostericola & $149,15,0(2)$ & $366,23,4(2)$ & $151,10,0(2)$ & $368,19,3(2)$ & $258,49,0(2)$ & $109,73,0(2)$ & $300,220(2)$ \\
\hline Palaemonetes vulgaris & $173,7,0(4)$ & $332,27,4(5)$ & $47,0,0(4)$ & $10,0,0(3)$ & $33,2,0(4)$ & $1,1,0(3)$ & $5,3(6)$ \\
\hline Penaeus duorarum & $7,0,0(11)$ & $5,0,1(11)$ & $17,1,0(21)$ & $21,3,0(6)$ & $262,61,9(9)$ & $33,17,0(7)$ & $2,1(26)$ \\
\hline Alpheus normanni & $7,0,0(5)$ & $7,0,0(10)$ & $5,0,0(5)$ & $109,2,1(4)$ & $212,4,0(5)$ & $0,4,0(3)$ & $12,2(4)$ \\
\hline Periclimenes longicaudatus & $5,2,0(3)$ & $29,2,1(3)$ & $1,0,0(4)$ & $3,4,9(4)$ & $18,27,0(3)$ & $175,248,0(2)$ & $0,1(4)$ \\
\hline Penaeus aztecus & & & $2,0,0(16)$ & $134,29,0(6)$ & $2,0,1(8)$ & $1,1,0(6)$ & $2,22(9)$ \\
\hline Tozeuma carolinense & $25,6,0(5)$ & $1,0,0(6)$ & $25,13,0(8)$ & $68,9,1(6)$ & $11,32,9(5)$ & $5,23,0(4)$ & $10,19(2)$ \\
\hline Alpheus heterochaelis & & & & $63,0,0(4)$ & $59,0,0(99)$ & & $2,0(2)$ \\
\hline Palaemonetes pugio & $6,0,0(3)$ & $33,0,0(5)$ & $11,0,0(4)$ & $46,2,1(2)$ & $9,0,1(2)$ & & $19,14(3)$ \\
\hline Palaemonetes intermedius & $12,0,0(4)$ & $33,0,0(4)$ & $18,0,0(4)$ & $24,0,0(2)$ & $6,0,0(3)$ & & \\
\hline Latreutes parvulus & & & & $1,0,0(2)$ & & $45,48,0(2)$ & \\
\hline Latreutes fucorum & & & & & $1,0,0(3)$ & $29,9,0(3)$ & \\
\hline Sicyonia laevigata & & & & & & $23,29,0(4)$ & \\
\hline Penaeus setiferus & & & & $10,0,0(3)$ & & & \\
\hline Hippolyte curacaoensis & & & & & & $9,12,0(2)$ & \\
\hline Parapenaeus politus & & & & & $0,1,0(2)$ & & \\
\hline Squilla empusa & & & & $1,0,0(5)$ & & & \\
\hline Thor dobkini & & & & & & $1,0,0(2)$ & \\
\hline Unidentified shrimp & & & & $2,0,0(4)$ & $1,2,0(7)$ & & \\
\hline
\end{tabular}

parison of size differences among treatments. Although many portunid, pagurid, and xanthid crabs were taken in the samples, the seines and dip nets were incon- sistent in collecting these organisms when they burrowed. Therefore, neither they, nor the few (18) Callinectes sp. collected, are considered further here. 

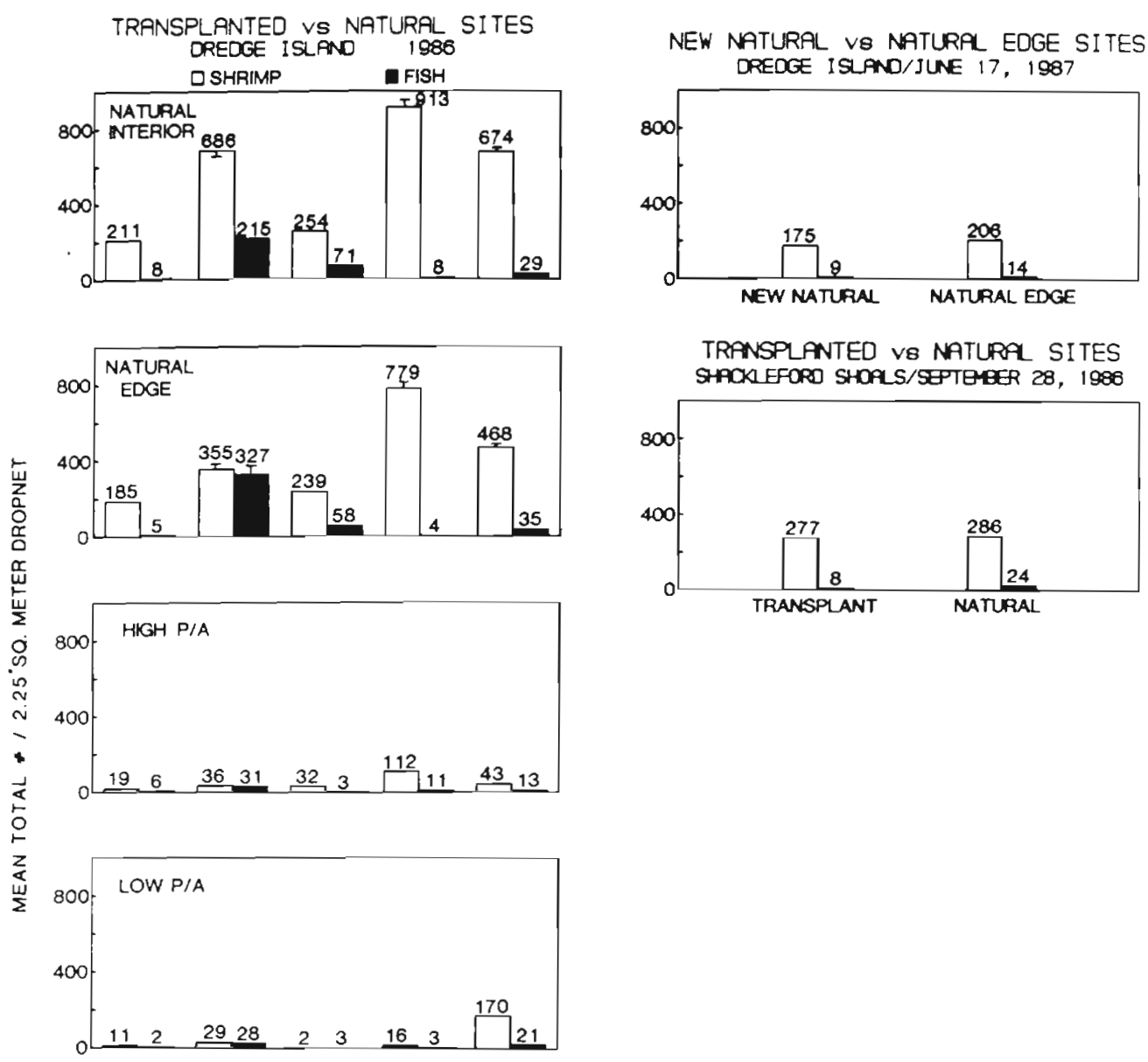

TRANSPLANTED VB NATLRA SITES

SHAKLEFORO SHORLS/SEPTEMER 28, 1986
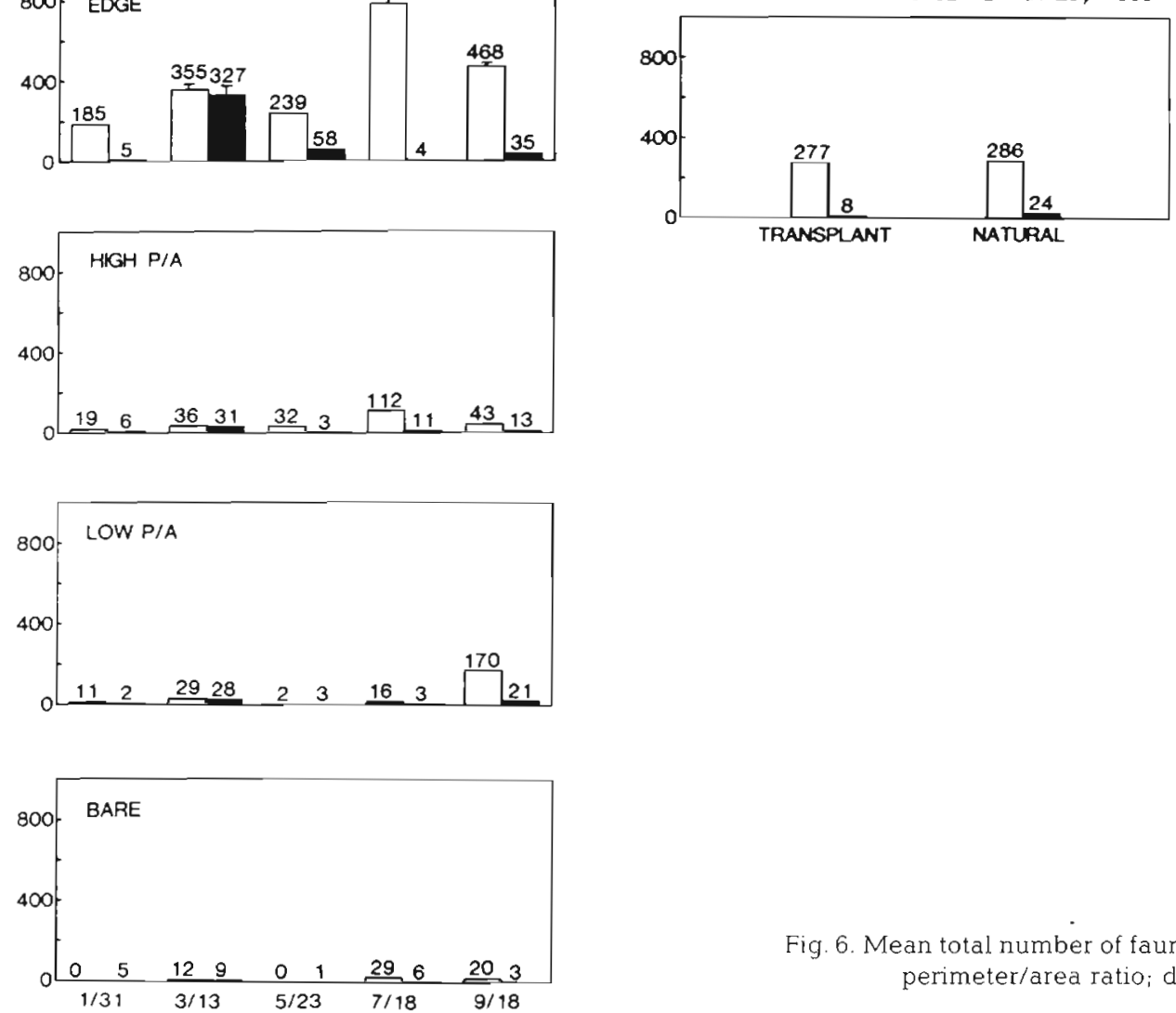

Fig. 6. Mean total number of fauna per $2.25 \mathrm{~m}^{2}$ dropnet. $\mathrm{P} / \mathrm{A}=$ perimeter/area ratio; dates are month/day

Dredge Island

Throughout the 1986 sampling period, numerical abundances of fauna in the transplanted areas were higher than in the adjacent bare areas (Fig. 6). The numbers of fish and shrimp fluctuated with peaks occurring in March and July-September, respectively, for fish and shrimp. On any given date, faunal abundances at the transplanted and bare areas were much lower than at the natural edge and natural interior treatments.

Analyses of variance revealed significant $(p<0.05)$ among-treatment differences in shrimp abundance for each of the 5 sampling periods of 1986 (Table 2, Fig. 6). Generally, shrimp were most abundant in the natural interior treatment, followed by the natural edge, high
P/A, low $\mathrm{P} / \mathrm{A}$, and bare area treatments, respectively. In January, May and September there were significantly higher numbers of shrimp in the 2 natural bed treatments than in the transplanted and bare area treatments. In March the natural interior treatments had twice the number of shrimp as the natural edge while in July substantial numbers were found in the transplants and bare areas as well.

For total fish abundance, fewer among-treatment differences were detected (Table 2, Fig.6). In fact, the analyses of variance provided no separation of treatment means for the January and July samples when only 26 and 29 fish, respectively, were collected. Fish usually were most abundant in the natural edge treatment, followed by natural interior, high $\mathrm{P} / \mathrm{A}$, low $\mathrm{P} / \mathrm{A}$, and bare area treatments, respectively. 
Table 2. Results of ranked Student Neuman-Keul's test. Bars connect treatment comparisons that are not significantly different at the $p<0.05$ level; dashed line crosses areas of significant difference to join treatments which are not different. Treatments: ni, natural interior of the natural eelgrass bed (>15 m from edge); ne, within $7.5 \mathrm{~m}$ of the edge of the natural eelgrass bed; hp, high perimeter to area (P/A) eelgrass transplant; lp, low P/A eelgrass transplant; ba, unvegetated bare area

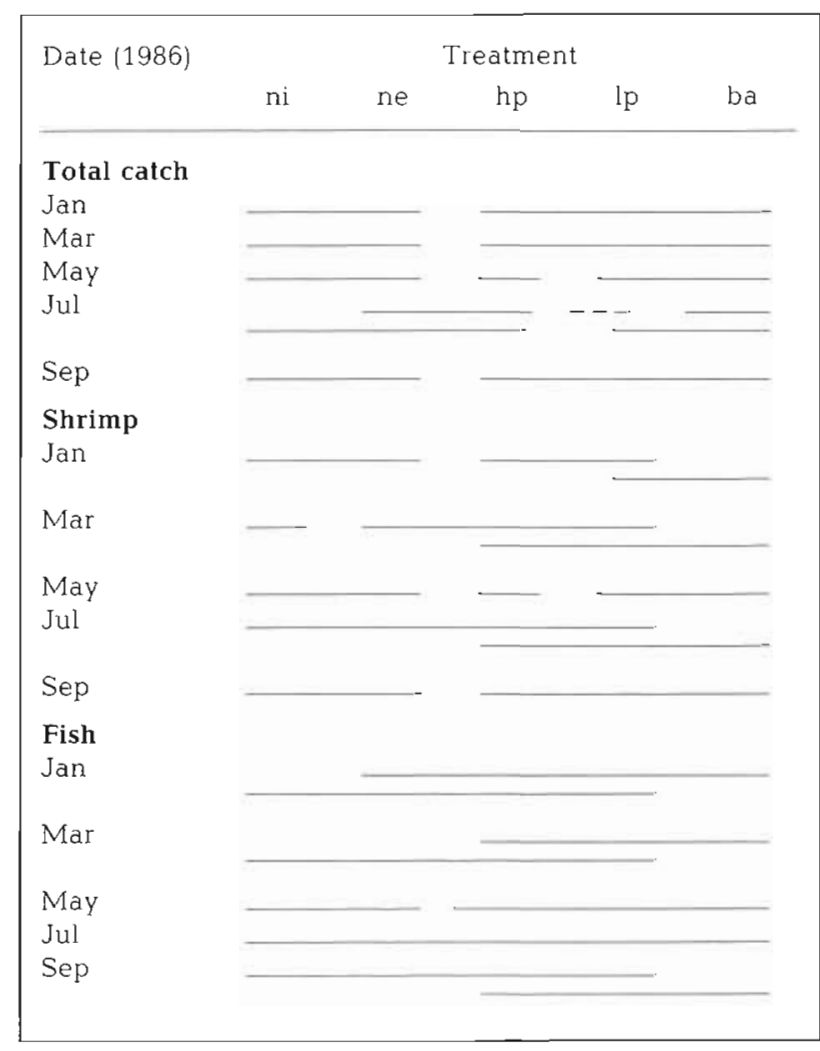

Shrimp numbers increased from January to March (Table 1b), at which time an influx of Leiostomus xanthurus and Lagodon rhomboides (14 to $17 \mathrm{~mm} \mathrm{SL}$ ) occurred. Also, the number of fish species on the site increased from 6 to 13 (Table 1a). By May, the abundance of shrimp and fish had decreased dramatically. Shrimp abundance rose substantially in July concomitant with low fish abundance. The high shrimp numbers in July were composed largely of Hippolytidae and Palaemonidae. Shrimp declined by ca $30 \%$ in September, simultaneous with an increase in fish numbers. These trends were most clearly evident in the natural beds where eelgrass abundance was consistently greater. Similar trends were observed on the transplanted areas, even though there was substantially less eelgrass present (Fig.5). In the bare, unplanted areas there was a trend of increasing numerical abundance of shrimp as the year progressed.

Because of the small numbers of individual fish captured, we did not conduct statistical comparisons of size differences between treatments. We observed that later in the summer of 1986, Lagodon rhomboides and Orthopristes chrysoptera were larger in the natural bed relative to the transplants (Table 1a). However, for other fish species (e.g. Symphurus plagiusa), the opposite was true. At the same time, the shrimp species Penaeus aztecus and $P$. duorarum averaged 7.7 and $11.1 \mathrm{~mm}$ SCL in natural beds versus 6.3 and $10.1 \mathrm{~mm}$ in bare areas and transplants (Table $1 b$ ). The only other shrimp species displaying a size difference by treatment was Tozeuma carolinense which averaged $6.5 \mathrm{~mm}$ SCL in natural beds versus $4.9 \mathrm{~mm}$ in bare areas and transplants

In June 1987, the numerical abundances of fish and shrimp in the recently seeded, new natural area (nns) were 85 and $64 \%$, respectively, of the numbers found in the natural edge area (nne) (Fig. 6). These numbers were similar to the May natural edge samples of the previous year. However, there were only 7 species of fish captured in 1987 versus 11 in May 1986, with only 3 of these species common to both years. For those 3 species, average sizes were larger in June 1987 than May 1986 (Table 1a). In contrast, shrimp size, abundance, and species composition were very similar between June 1987 and May 1986 (Table 1b).

\section{Shackleford Shoals}

Numerical abundance of shrimp was almost identical between natural and 1.9-yr-old transplanted eelgrass at this site (Fig. 6). Shrimp abundance at this site was only about half that of the Dredge Island natural eelgrass treatments in September. Fish abundance was 3 times greater in the natural beds than in the transplants, although these values were within the range of September values for both sites. No fauna were captured in the bare area nets on this site (Table 1a, b).

\section{Similarity of treatments}

The percentage similarity (PSIL) and percent species shared (PSS) among treatments were computed independently for the Dredge Island site, January through September 1986, Dredge Island June 1987 and the Shackleford site. The Dredge Island collection was composed of 55 species of which $29(53 \%$ of the species) constituted $99 \%$ of the catch. At the Dredge Island in $1987,99 \%$ of the catch was contributed by 18 of the 29 species $(63 \%)$ while 14 of 22 species $(64 \%)$ comprised $99 \%$ of the catch at the Shackleford site.

At the Dredge Island site in 1986 the natural edge and natural interior treatments had the highest PSIL and PSS values of all combinations (Table 3 ). This 
Table 3. Percentage similarity (after Whittaker \& Fairbanks 1958) and in parentheses, the percentage of species shared. Computations run on the species that composed $99 \%$ of the catch by site. ni, natural interior of the natural eelgrass bed (>15 m from edge); ne, within $7.5 \mathrm{~m}$ of the edge of the natural eelgrass bed; $h$, high perimeter to area (P/A) eelgrass transplant; lp. low P/A eelgrass transplant; ba, unvegetated bare area

\begin{tabular}{|c|c|c|c|c|c|}
\hline \multicolumn{6}{|c|}{ Dredge Island (Jan vs Sep 1986) } \\
\hline & $\mathrm{ni}$ & ne & hp & $\mathrm{Ip}$ & ba \\
\hline ni & - & $82(78)$ & $72(52)$ & $64(60)$ & $53(48)$ \\
\hline ne & & - & $68(63)$ & $60(70)$ & $51(56)$ \\
\hline hp & & & & $74(63)$ & $66(52)$ \\
\hline $\operatorname{lp}$ & & & & - & $75(56)$ \\
\hline ba & & & & & - \\
\hline \multicolumn{6}{|c|}{$\begin{array}{l}\text { Dredge Island (June 1987) } \\
\text { Natural edge vs natural seeded area } \\
\qquad 77 \text { (86) }\end{array}$} \\
\hline \multicolumn{6}{|c|}{$\begin{array}{c}\text { Shackleford Shoals (Sep 1986) } \\
\text { Natural patch vs 1.9-yr-old transplant } \\
90(89)\end{array}$} \\
\hline
\end{tabular}

indicated that with $78 \%$ of the 29 species occurring in both treatments, the relative numerical distribution among the shared species was similar between the 2 treatments (PSIL $=82$ ). These natural treatments had little similarity with the bare area (PSIL and PSS $=\mathrm{ca}$ 50). Although a low percentage of the species were shared, the bare area and transplants had a higher relative numerical distribution (PSIL $=$ ca 70 ) as compared with the natural treatments. The transplanted treatments were also similar to each other in terms of relative numerical distribution (PSIL $=74$ ) while sharing only $63 \%$ of the species.

In contrast to the natural and transplant comparisons at the Dredge Island in 1986, a comparison of the same area in June 1987 after the natural seeding event yielded a PSIL of 77 with $86 \%$ of the species shared (Table 3). Similarly, the comparison at the Shackleford site after $1.9 \mathrm{yr}$ produced a PSIL of 90 with $89 \%$ of the species shared.

\section{Vector-graphical analysis}

A vector graph of average numbers of individual organisms versus average numbers of shoots per dropnet sample is shown in Fig. 7. In a similar comparison (not presented) using standardized area of eelgrass cover $\left(\mathrm{m}^{2}\right)$, all vectors were oriented vertically, indicating no real contribution by area covered (the dependent variable). In contrast, standardized shoot numbers

$$
\begin{gathered}
\text { Dates of the } 5 \text { Connected Samples - Treatment }{ }^{-1} \\
1 / 31 / 86,3 / 21,5 / 23,7 / 18,9 / 18
\end{gathered}
$$

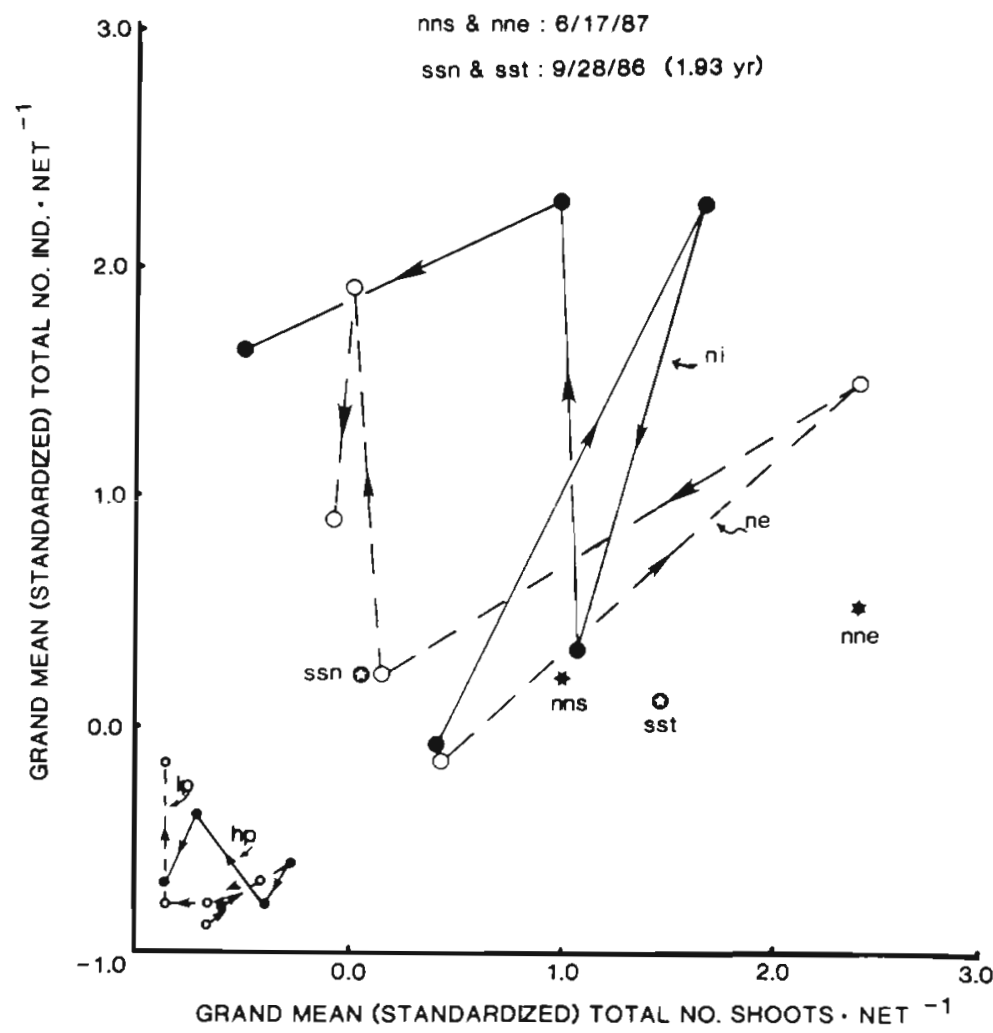

Fig. 7. Vector graphical analysis. Dredge Island eelgrass treatment codes: $\mathrm{ni}$, natural interior; ne, natural edge $; \mathrm{hp}$, high perimeter/area (P/A) transplant; lp, low P/A; nne, new natural edge; nns, new naturally seeded. Shackleford Shoals: ssn, natural; sst, transplanted 
(density) produced effects on vector orientation. The relative paucity of both organisms and shoots in the transplant samples restricts their vectors to the lower left portion of the graph (Fig. 7). The vector for the natural edge samples shows a proportionate increase in both floral and faunal components between late January and March. A proportionate decrease occurred during the following $2 \mathrm{mo}$, after which the shoot density remained stable during a substantial fluctuation in the fauna, reflecting a transient increase in postlarval Lagodon rhomboides and Leiostomus xanthurus. For the interior of the natural beds, the increase in fauna from January to March was greater than the increase in shoot density. During the following 4 mo the fluctuations in fauna relative to changes in shoot numbers were even more disproportionate. During late summer, organism densities remained relatively high even though shoot densities declined to about the level observed earlier in the year in the transplanted beds. Finally, plots of single points for the naturally seeded beds in June 1987 (nns) and for the Shackleford Shoals site in September (ssn) show close congruence with observations from natural eelgrass beds made about a year earlier at the Dredge Island. This congruence indicates that, after $1.9 \mathrm{yr}$, the Shackleford site had a faunal abundance/shoot ratio equivalent to natural beds, a phenomena which occurred in as little as 6 mo in the naturally seeded bed.

\section{DISCUSSION}

Environmental conditions at the Dredge Island during 1986 appeared to be stressful for eelgrass. Eelgrass population growth rates at this site were among the worst observed in North Carolina (Fonseca et al. 1985). The high loss of transplants precluded comparison of transplanting arrangement (high perimeter vs low perimeter) and impaired our ability to evaluate any developmental sequences in the transplant treatments based on this site alone. While the natural eelgrass bed at the Dredge Island was diminished in density, changes in area covered by eelgrass were not as dramatic as in the transplants (Fig. 4). In the transplanted beds, however, area covered was much more closely linked to numbers of shoots. Areal coverage decreased along with the decline in shoots to the point where transplanted material was completely lost by September 1986 (Fig. 4).

Although developmental comparisons were inpaired, some clear patterns of faunal abundance emerged. Within the sizes of organisms we captured at the Dredge Island in 1986, there were clearly greater abundances in the natural eelgrass areas than the adjacent transplanted and bare areas (Table 2, Fig. 6). The species captured, their size range and change in size over the year (Table $1 \mathrm{a}, \mathrm{b}$ ) are consistent with the findings of other investigators in natural eelgrass systems (Thayer et al. 1975. Adams 1976, Orth \& Heck 1980, Weinstein \& Brooks 1983). Also, for some species, there was a tendency toward larger individuals being found in the natural eelgrass beds.

Smaller average size for some fauna in areas of little or no vegetation may be the result of several factors: more recent recruitment (thus smaller size classes), differential predation on larger individuals within a species, a scaling of an individuals' size to habitat complexity, intraspecific competition relegating smaller individuals to less optimal habitat, or conversely, size-specific emigration of larger individuals to other locations (Sogard 1989). Peaks in some prey (Hippolyte sp.) abundance were followed by peaks in predator (fish) abundance, a phase shift which definitely evokes predation as a potential factor controlling shrimp abundance (Sheridan \& Livingston 1983). Such a phase shift also could be the result of natural mortality and/or immigration/emigration factors. Determining which of these mechanisms contribute to observed faunal abundance is an important next step in restoration research. Whereas static measures of abundance could be construed as indicative of low habitat value, low numbers as a result of one of these mechanisms (e.g. intense predation or selective emigration) would indicate high functional value. Abundance data need to be interpreted through functional mechanisms in order to separate habitat function from dysfunction.

During the period that eelgrass cover and shoot abundance were declining at the Dredge Island site, the Shackleford Shoals site displayed comparatively high cover and shoot numbers, nearly equivalent to pre-June levels at the Dredge Island site (Fig. 5), allowing us to use the site as a potential end-point comparison. Because of differences in environmental conditions, such as proximity to Beaufort Inlet, the degree of faunal development may be inherently different between the 2 sites. Such a difference is supported by the higher diversity and abundance of tropical shrimp species caught at Shackleford in the late summer as compared to the Dredge Island site (Table 1b). Differences in meadow form (patchy at Shackleford vs continuous at the Dredge Island) also may provide unequal faunal habitat utilization potentials (Fonseca et al. 1983). However, because numerical abundance and composition at the Shackleford site and the 1987 Dredge Island seeded bed apparently had converged with natural bed values, a stronger argument can be made for accepting such convergence as a useful generalization.

In examining faunal abundance there was an apparent affinity of fauna for even the slightest amount of 
eelgrass (Bell \& Westoby 1986, Sogard 1989). This was particularly evident when transplanted eelgrass abundance at the Dredge Island was waning (Fig. 6). This corroborates previous observations of a strong positive relationship between macroinvertebrates (e.g. Argopecten irradians) and eelgrass planting units (Kenworthy et al. 1980, Homziak et al. 1982, Smith et al. 1989). Also, after 1.9 yr of transplant development at the Shackleford Shoals site, the numerical abundance and species composition between natural and transplanted beds was virtually indistinguishable. Such a trend would be consistent with the findings of McLaughlin et al. (1983) for infauna and otter-trawled macrobenthos in a restored Thalassia bed. If we posit that the high affinity for eelgrass shoots by fauna were to continue, then a logical assumption would be that when the eelgrass population stabilized, the faunal population would too. This would explain the apparent convergence of faunal structure between the shoal transplant and natural shoal eelgrass bed samples ca 2 yr after planting while the Dredge Island site had numerically lower faunal abundance and suffered from severe eelgrass mortality.

Faunal colonization of the newly seeded area at the Dredge Island in 1987 also supports the observation of community convergence observed at the Shackleford Shoals site. The seed set provided a natural analog (although compressed in time) of community development in a successful transplant. Rapid faunal development in the seeded area suggests that the rate-limiting factor for faunal development can be, as intuitively suspected, eelgrass shoot abundance. The time of year when transplants (or seed sets) occur also may be critical in that plants must be sufficiently developed to influence faunal distribution. In general, successful seed sets over large areas of historically unvegetated bottom are rare events in this area. To transplant mature, vegetative shoots (as the technology currently demands) at the densities achieved by the seed set is economically unfeasible. These data suggest that use of eelgrass seed to create new beds may achieve faunal recovery much more rapidly than conventional techniques. Research by Riner (1976), Roberts et ai. (1984), and Orth (pers. comm.) demonstrate that eelgrass seeding techniques are not yet perfected, but show promise.

The vector-graphical analysis (Fig. 7) provided a composite basis for evaluation of transplant success based on both flora and fauna. It revealed, for example, that by June 17,1987, the new, naturally seeded area at the Dredge Spoil island had already, within the space of several months, attained a position within the range of values occupied by the natural interior treatment about 3 wk earlier At any point in time comparative treatments (ni vs ne; nne vs nns; ssn vs sst) had similar numbers of fauna despite relatively large differences in shoot abundance. We interpret this spread to represent the natural variation in the distribution of fauna at this scale.

The vector-graphical approach suggests an alternative method to quantifying the ecological, successional maturity of an artificially propagated habitat. That is to say, the functional equivalence of natural and transplanted beds is not measured solely by comparison to some constant level, but instead in terms of the overlap of the faunal/shoot abundance ratio between the natural and transplanted eelgrass beds. The gradual coming into phase of the distribution of points from transplanted beds with natural beds is interpreted as increasing ecological maturity, making coherence of the ratios across seasons a quantitative measure of how functionally equivalent (at least in terms of a size range of epibenthic fauna) the 2 habitats are at a given point in time. This assessment is consistent with the conclusions of numerous investigators where standing crop of seagrass was a primary determinant of faunal density (Heck \& Wetstone 1977, Heck \& Orth 1980, Stoner 1980, 1983, Lewis 1984, Orth et al. 1984, Stoner \& Lewis 1985, Sogard et al. 1987, Sogard 1989). If this relationship can be demonstrated in other seagrass habitats, and the rate of development documented, managers would be in a position to accept evaluation of shoot development over a prescribed period of time to provide reasonable assurance of functional habitat recovery as measured by macroepifaunal abundance and composition.

Composition of the fauna and not just the numerical abundance must be considered if trophodynamic conditions are to be preserved. We note also that the distribution of species and individuals became balanced between natural and transplanted eelgrass on the Shackleford Shoals site as well as between the seeded and natural beds at the Dredge Island in 1987 (Table 3). These data demonstrate that a high number of species were shared between the natural and transplanted beds and that the species that were shared occurred in similar numerical proportion among the treatments. These data provide evidence for convergence of composition as well as total number of individuals. The contrast in percentage similarity and percent species shared among treatments at different stages of development was clearly detectable and is an important diagnostic parameter to be used in conjunction with numerical developmental trajectories in evaluating functional equivalency. This convergence in numbers and composition was observed for forage species as well as economically valuable species.

In contrast to a study by Heck \& Thoman (1984) in Chesapeake Bay, we found economically valuable species (EVS), especially penaeid shrimp, to be a persistent and substantial part of the faunal assemblage 
(Table 1b). EVS recruited relatively quickly to the eelgrass beds established through transplantation at the Dredge Island, although they did not attain as high densities as in the adjacent natural beds or in the older (transplanted) beds at Shackleford Shoals.

Clearly, much remains to be learned about ecological functions of artificially-established seagrass beds and unvegetated substrates before the issue of adequate mitigation for habitat loss through seagrass restoration/ creation can be satisfactorily resolved. Answers to many of the questions will require direct measures of competition and rates of predation, rather than simple measures of standing crop. Through this approach, we will be able to evaluate the efficacy of using eelgrass abundance and persistence alone as indicators of restoration success. While the current study failed to provide sufficient insight into the relative roles of patchy versus continuous bedforms, we consider that topic deserving of high priority. While eelgrass beds are viewed as important biological production systems, we have to recognize the fact that beds developed through transplantation require time to attain mature productive capabilities. Obviously, transplant persistence through time must be incorporated as a criterion in evaluation of the success of future restoration/creation projects. Given that under present management applications there has not been any seagrass transplant that has returned acreage even equal to that which was lost (Fonseca et al. 1987), and that faunal abundance is closely tied to plant abundance, eelgrass transplanting as a mitigative trade-off for existing beds may be resulting in a net loss of faunal abundance, including economically valuable species.

Acknowledgements. Thanks are extended to C. Currin, B. A. France, D. Jacobson, M. LaCroix, P. Marraro, D. Meyer, J. Rivera, I. Smith, and V. Thayer for their assistance in sampling. Reviews by A. Chester, C. Currin, S. Ross, R. Zimmerman and 3 anonymous reviewers improved the manuscript. $H$. Gordy prepared the graphics. Partial funding was provided by the U.S. Army Corps of Engineers, Waterways Experiment Station. Primary support was provided by the National Marine Fisheries Service, NOAA.

\section{LITERATURE CITED}

Adams, S. M. (1976). The ecology of eelgrass, Zostera marina, fish communities. I. Structural analysis. J. exp. mar. Biol. Ecol. 22: 269-291

Bell, J. D., Westoby, M. (1986). Abundance of macrofauna in dense seagrass is due to habitat preference, not predation. Oecologia (Berl.) 68: 205-209

Folk, R. L., Ward, W. C. (1957). Brazos River Bar: a study in the significance of grain size parameters. J. sedim. Petrol. 27 : $3-26$

Fonseca, M. S., Kenworthy, W. J., Thayer, G. W. (1982). A lowcost planting technique for eelgrass (Zostera marina). U.S. Army Corps of Engineers Technical Aid No. 82-6
Fonseca, M. S., Zieman, J. C., Thayer, G. W., Fisher, J. S. (1983). The role of current velocity in structuring eelgrass (Zostera marina) meadows. Estuar. coast. Shelf Sci. 17 $367-380$

Fonseca, M. S., Kenworthy, W. J., Thayer, G. W., Heller, D. Y., Cheap. K. M. (1985). Transplanting of the seagrasses Zostera marina and Halodule wrightii for sediment stabilization and habitat development on the east coast of the United States. U.S. Army Corps of Engineers Technical Report EL-85-9

Fonseca, M. S., Kenworthy, W J., Rittmaster, K., Thayer, G. W. (1987). The use of fertilizer to enhance transplants of the seagrasses Zostera marina and Halodule wrightii. U.S. Army Corps of Engineers Technical Report EL-87-12

Fonseca, M. S., Thayer, G. W., Kenworthy W. J. (1988). Restoration and management of seagrass systems: a review. In: Hook, D. D., et al. (eds.) The ecology and management of wetlands, Vol. 2. Management, use and value of wetlands. Timber Press, Portland, p. 353-368

Heck, K. L., Orth, R. J. (1980). Seagrass habitats: the roles of habitat complexity, competition and predation in structuring assisted fish and motile macroinvertebrate assemblages. In: Kennedy, V. S. (ed.) Estuarine perspectives. Academic Press, New York, p. 449-4.64

Heck, K. L., Thoman, T A. (1984). The nursery role of seagrass meadows in the upper and lower reaches of the Chesapeake Bay. Estuaries 7: 70-92

Heck, K. L., Wetstone, G. S. (1977). Habitat complexity and invertebrate species richness and abundance in tropical seagrass meadows. J. Biogeogr. 4: 135-142

Holmquist, J. G., Powell, G. V N., Sogard, S. M. (1989). Decapod and stomatopod assemblages on a system of seagrass-covered mud banks in Florida Bay. Mar. Biol. 100: $473-483$

Homziak, J., Fonseca, M. S., Kenworthy, W. J., Thayer, G. W. (1982). Macrobenthic community structure in a transplanted eelgrass (Zostera marina) meadow. Mar. Ecol. Prog. Ser. 9: 211-221

Jacobsen, T., Kushlan, J. A. (1987). Sources of sampling bias in enclosure fish trapping: Effects on estimates of density and diversity. Fish. Res. 5: 401-412

Kenworthy, W. J., Fonseca, M. S., Homziak, J., Thayer, G. W. (1980).Development of a transplanted seagrass (Zostera marina L.) meadow in Back Sound, Carteret County, North Carolina. In. Cole, D. P. (ed) Proc. 7 th Ann. Conf. on the Restoration and Creation of Wetlands. Hillsborough Comm. Coll., Tampa, p. 175-193

Lewis, F. G. (1984). Distribution of macrobenthic crustaceans associated with Thalassia, Halodule and bare sand substrata. Mar. Ecol. Prog. Ser 19: 101-113

Mager, A., Thayer, G. W (1986). National Marine Fisheries Service habitat conservation efforts in the southeast region of the United States from 1981 through 1985. Mar. Fish. Rev. 48 (3): $1-8$

McLaughlin, P. A., Treat, S. F., Thorhaug, A., Lemaitre, R. (1983). A restored seagrass (Thalassia) bed and its animal community. Environ. Conserv. 10: 247-254

Orth, R. J., Heck, K. L. (1980). Structural components of eelgrass (Zostera marina) meadows in the lower Chesapeake Bay - fishes. Estuaries 3: 278-288

Orth, R. J., Heck, K. L., Van Montfrans, J. (1984). Faunal communities in seagrass beds: a review of the influence of plant structure and prey characteristic on predator-prey relationships. Estuaries 7: 339-350

Race, M. S., Christie, D. R. (1982). Coastal zone development: Mitigation, marsh creation and decision-making. Environ. Mgmt. 6: 317-328 
Riner, M. I. (1976). A study on methods, techniques and growth characteristics for transplanted portions of eelgrass (Zostera marina). M.S. Thesis, Adelphi Univ., Garden City, N.Y

Roberts, M. H., Orth, R. J., Moore, K. A. (1984). Growth of Zostera marina $\mathrm{L}$. seedlings under laboratory conditions of nutrient enrichment. Aquat. Bot. 20: 321-328

Sheridan, P. A., Livingston, R. J. (1983). Abundance and seasonality of infauna and epifauna inhabiting a Halodule wrighti meadow in Apalachicola Bay, Florida. Estuaries 6: 407-419

Smith, I., Fonseca, M. S., Rivera, J. A., Rittmaster, K. R. (1989). Habitat value of natural versus recently transplanted eelgrass, Zostera marina for the bay scallop. Argopecten irradians. Fish. Bull. U.S. 87: 189-196

Sogard, S. M. (1989). Colonization of artificial seagrass by fishes and decapod crustaceans: importance of proximity to natural eelgrass. J. exp. mar. biol. Ecol. 133: 15-37

Sogard, S. M., Powell, G. V N., Holmquist, J. G. (1987). Epibenthic fish communities on Florida Bay banks: relations with physical parameters and seagrass cover. Mar Ecol. Prog. Ser. 40: 25-39

Stoner, A. W (1980). The role of seagrass biomass in the organization of benthic macrofaunal assemblages. Bull. mar Sci. 30: 537-551

This article was submitted to the editor
Stoner, A. W. (1983). Distribution of fishes on seagrass meadows: role of macrophyte biomass and species composition. Fish. Bull. U. S. 81: 837-846

Stoner, A. W., Lewis, F. G. (1985). The influence of quantitative and qualitative aspects of habitat complexity in tropical seagrass meadows. J. exp. mar. biol. Ecol 94 $19-40$

Thayer, G. W., Adams, S. M., LaCroix, M. W. (1975). Structural and functional aspects of a recently established Zostera marina community. Estuarine research, Vol. I. Academic Press, New York, p. 518-540

Thayer, G. W., Kenworthy, W J., Fonseca, M. S. (1984). The ecology of eelgrass meadows of the Atlantic coast: a community profile. U. S. Fish Wildl. Serv. FWS/OBS-84/02

Weinstein, M. P., Brooks, H. A. (1983). Comparative ecology of nekton residing in a tidal creek and an adjacent seagrass meadow: Community composition and structure. Mar. Ecol. Prog. Ser 12: 15-27

Whittaker, R. H., Fairbanks, C. W. (1958). A study of plankton copepod communities in the Columbia Basin, southeastern Washington. Ecology 39:46-65

Zieman, J. C. (1982). The ecology of the seagrasses of south Florida: a community profile. U.S. Fish Wildl. Serv. FWS/ OBS-82/25

Manuscript first received: February 21, 1989

Revised version accepted: May 21, 1990 